\title{
Full-Scale Tests to Failure Compared to Assessments - Three Concrete Bridges
}

\author{
Niklas Bagge $^{1}$, Jonny Nilimaa ${ }^{1}$, Arto Puurula ${ }^{1}$, Björn Täljsten ${ }^{1}$, \\ Thomas Blanksvärd ${ }^{1}$, Gabriel Sas ${ }^{1}$, Lennart Elfgren ${ }^{1(\bowtie)}$, \\ and Anders Carolin ${ }^{2}$ \\ 1 Department of Civil Environmental and Natural Resources Engineering, \\ Luleå University of Technology, 97187 Luleå, Sweden \\ \{Niklas. Bagge, Jonny. Nilimaa, Arto. Puurula, Bjorn. \\ Taljsten, Thomas. Blanksvard, Gabriel. Sas, \\ Lennart.Elfgren\}@ltu.se \\ 2 Trafikverket, 97125 Luleå, Sweden \\ Anders.Carolin@trafikverket.se
}

\begin{abstract}
Three Swedish concrete bridges have been tested to failure and the results have been compared to assessment using standard code models and advanced numerical methods.

The three tested and assessed bridges were:

(1) Lautajokk, a 29 year old one span $(7 \mathrm{~m})$ concrete trough bridge tested in fatigue to check the concrete shear capacity.

(2) Örnskldsvik, a 50 year old two span trough bridge $(12+12 \mathrm{~m})$ strengthened to avoid a bending failure.

(3) Kiruna Mine Bridge, a 55 year old five span prestressed concrete road bridge $(18+21+23+24+20 \mathrm{~m})$ tested in shear and bending of the beams and punching of the slab.

The main results in the paper are the experiences of the real failure types, the robustness/weakness of the bridges, and the accuracy of different codes and models. In all three cases the bridges had a considerable hidden capacity.
\end{abstract}

Keywords: Assessment $\cdot$ Codes $\cdot$ Concrete bridges $\cdot$ Full-scale tests $\cdot$ Failure modelling

\section{Introduction}

Assessment of the load-carrying capacity of existing bridges is an important task. Three concrete bridges have been tested to failure and the results have been compared using standard code models and advanced numerical methods. The results may help to make more accurate assessments of similar existing bridges. There it is necessary to know the real behaviour, weak points, and to be able to model the load-carrying capacity in a correct way. 


\section{The Lautajokk Bridge}

\subsection{Background}

The railway line between Luleå and Narvik in northern Sweden and Norway was built 1884-1902 to transport iron ore from the mines in Kiruna and Gällivare to the harbours in the Baltic and the Atlantic. Originally the line was designed for an axle load of $140 \mathrm{kN}$. In 1960 it was raised to $250 \mathrm{kN}$ and in the 1990ies there was a wish to increase it to $300 \mathrm{kN}$. An investigation was carried out and as part of that a bridge from Lautajokk was tested for fatigue in 1996; see Fig. 1, Paulsson et al. (1996). The bridge was built in 1967, had a free span of $6,1 \mathrm{~m}$, a width of $4,1 \mathrm{~m}$, concrete quality K400 (40 MPa) and reinforcement Ks40 (yield strength $400 \mathrm{MPa}$ ). The bridge was in service between 1968 and 1988 and was then exchanged to improve the line geometry. The bridge had carried about 2,7 million cycles with $225 \mathrm{kN}$ axle load, Thun et al. (2000).

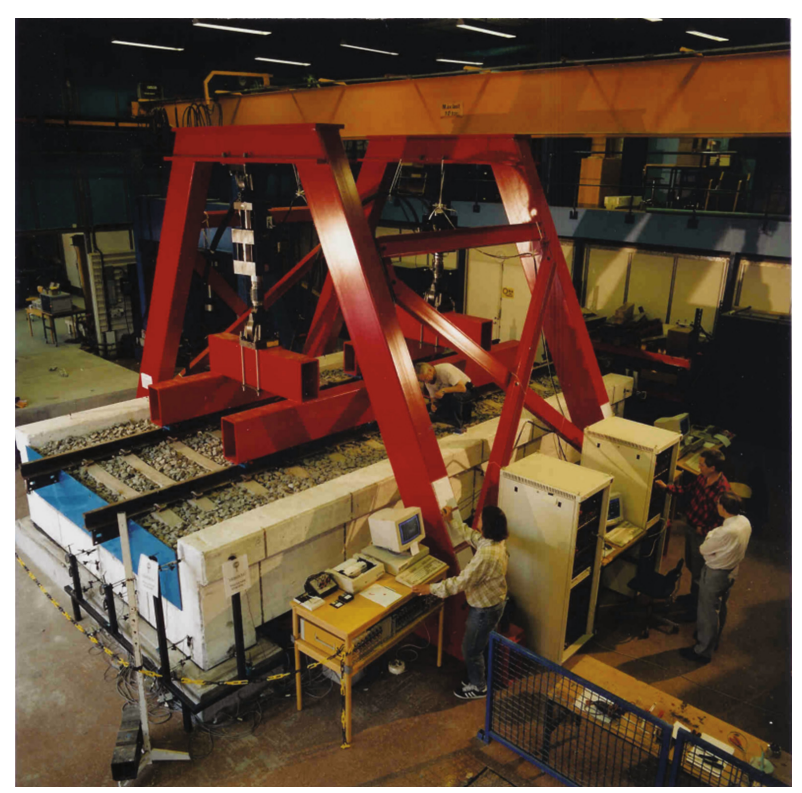

Fig. 1. Full Scale Test of a 29 year old Railway Trough Bridge at Luleå University of Technology. Paulsson et al. (1996); Thun et al. (2000).

\subsection{Experimental Program}

The bridge was loaded with 6 million cycles with an axle load of $1,2 \cdot 300=360 \mathrm{kN}$ (including a dynamic load factor of $20 \%$ ). The mid-point deflection is given in Fig. 2, left. Its increase with time is mostly due to creep in the concrete. No notable damages were observed and only hair line cracks appeared in the bottom of the slab. Finally the bridge was loaded to the maximum capacity of the jacks, $875 \mathrm{kN}$, see Fig. 2 right. A beginning of yielding in the reinforcement can be seen but the ultimate load capacity 
was probably slightly higher. After testing, 16 concrete cores were drilled out giving a compressive strength $f_{\mathrm{cc}}=72,6 \mathrm{MPa}$ (mean of 6 tests) in the slab and $f_{\mathrm{cc}}=81,2 \mathrm{MPa}$ ( 2 tests) in the beams and a tensile strength (splitting of four cylinders) $f_{\text {cspl }}=4,4 \mathrm{MPa}$ and a uniaxial tension strength $f_{\mathrm{ct}}=2,9 \mathrm{MPa}$.

\subsection{Assessment Versus Test Results}

The tests showed that the fatigue capacity of the bridge was much higher than what was predicted by the codes, Thun et al. (2000). Critical was the shear capacity in the connection of the slab to the longitudinal beams with no shear reinforcement in the slab. For concrete class C60 the Eurocode predicted 5,1 million cycles for $225 \mathrm{kN}$, 0,5 million cycles for $250 \mathrm{kN}$ and 0,012 million cycles for $300 \mathrm{kN}$. The fatigue capacity of concrete is further discussed in Thun et al. (2011) and Elfgren (2015).
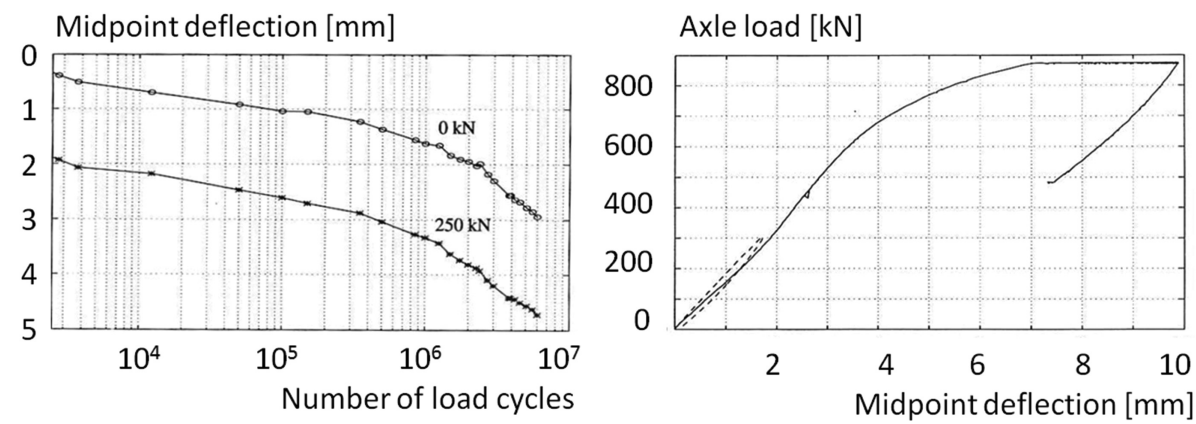

Fig. 2. Mid-point deflection. Left: At 0 and $250 \mathrm{kN}$ load for $6 \cdot 10^{6}$ load cycles with a maximum deflection of 4,8 mm. Right: Final loading to $875 \mathrm{kN}$ after 6 million cycles with $360 \mathrm{kN}$ axle load. Dashed line shows preloading to $300 \mathrm{kN}$.

\section{The Örnsköljdsvik Bridge}

\subsection{Background}

This test was scheduled as part of a demonstration of newly developed or upgraded tools for monitoring, assessment and upgrading of structures within the EU financed project Sustainable Bridges (2007); Paulsson et al. (2016), see Fig. 3.

The studied bridge was a 50 year old RC railway trough bridge located in Örnsköldsvik. The bridge consisted of two outer beams supporting a slab in two spans $(12+12 \mathrm{~m})$, with a slight longitudinal curvature $(\mathrm{R}=300 \mathrm{~m})$ and supports skewed with an angle of $17^{\circ}$. It was taken out of service in 2005 and tested to failure in 2006, Elfgren et al. (2008); Puruula (2012); Puruula et al. (2014; 2015; 2016). 


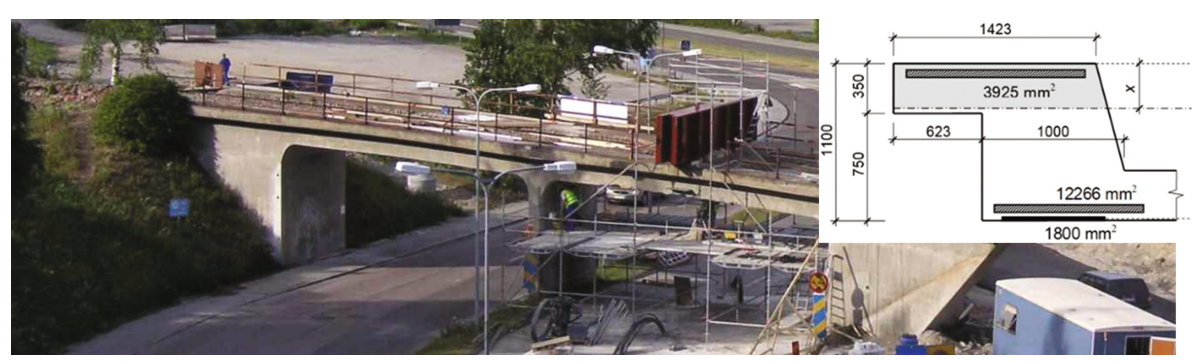

Fig. 3. The tested railway bridge in Örnsköldsvik, Sweden, in a view from the West side showing the test setup. A cross-section is shown as an insert.

\subsection{Experimental Program}

The bridge was designed for a $40 \mathrm{MPa}$ concrete and steel reinforcement with yield strength of $400 \mathrm{MPa}$. Tested concrete had a mean strength of 68,5 $\mathrm{MPa}$. The reason for the growth is a coarse grinding of the cement which prolonged the hydration process after the 28 days, when the original concrete was tested. The steel reinforcement tests showed yield strengths slightly above $400 \mathrm{MPa}$ and ultimate strengths up to $700 \mathrm{MPa}$. To obtain a shear failure, the bridge was strengthened before the final failure test with 18 (nine per beam) $10 \mathrm{~m}$ long near surface mounted (NSM) carbon fiber reinforced polymers (CFRP) bars, each with a $10 \times 10 \mathrm{~mm}$ cross section. The modulus of elasticity and the tensile strain at failure were $250 \mathrm{GPa}$ and $0,8 \%$, respectively.

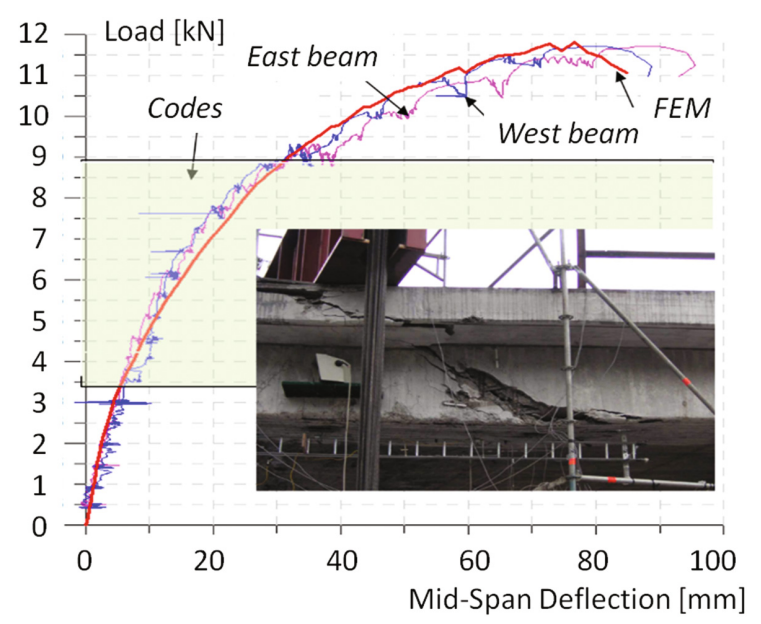

Fig. 4. Load-displacement curves as recorded and as calculated with codes and nonlinear FEM. Insert: crack pattern in the SE beam after failure. 
The bridge was tested with two hydraulic jacks, placed on top of a loading beam. They exerted a downward force on the loading beam by pulling on steel tendons anchored in the bedrock to a depth of $9 \mathrm{~m}$.

\subsection{Assessment Versus Test Results}

The failure was relatively ductile, Fig. 4. The recorded failure load $P$ was $11,7 \mathrm{MN}$. The mechanism of failure was a simultaneous bond-bending-shear failure, resulting in the formation of flexural-shear cracks in both beams at an angle of about $\theta \approx 32^{\circ}$. The NSM reinforcement played a major role in the failure process and initiated the shear-bending failure. Code failure load values varied between 3,5 and $9 \mathrm{MN}$.

\section{The Kiruna Bridge}

\subsection{Background}

A 55 year-old prestressed concrete girder bridge (see Fig. 5) was taken out of service due to large ground deformations caused by mining activities. However, the bridge was still in very good condition with only minor damages observed and, thus, it was decided to further study the bridge in order to examine and develop methods for assessment, Bagge et al. (2014, 2015, 2016); Nilimaa (2015) and Huang et al. (2016).

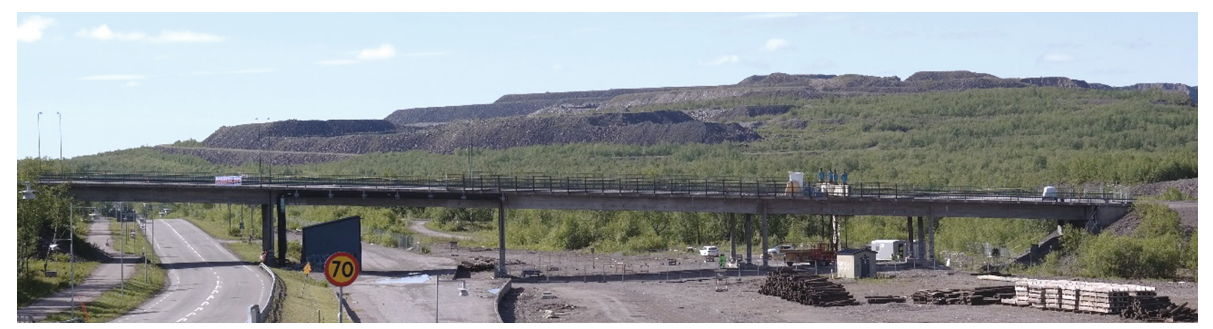

Fig. 5. Photograph of the Kiruna bridge, view from north.

The bridge was continuous over five spans with a total length of $121.5 \mathrm{~m}$. The superstructure consisted of three girders (width: 410-650 mm, height: $1923 \mathrm{~mm}$ ) connected with a slab (w: $14900 \mathrm{~mm}$, h: 220-300 mm) with curbs on either side (w: $300 \mathrm{~mm}$, h: $300 \mathrm{~mm}$ ) and was supported on columns and abutments. Four or six post-tensioned tendons, consisting of 32 strands (diameter: $6 \mathrm{~mm}$ ), was used in the girders. Design of the bridge was based on concrete compressive strength of 28.5 $\mathrm{MPa}$, the non-prestressed steel yield strengths of 400 or $600 \mathrm{MPa}$ and the prestressed steel $0.2 \%$ proof strength and tensile strength of $1450 \mathrm{MPa}$ and $1700 \mathrm{MPa}$, respectively. 


\subsection{Experimental Study}

Two of the three bridge girders were strengthened in the second span from west; Near Surface Mounted (NSM) Carbon Fibre Reinforced Polymer (CFRP) rods were installed in the concrete cover at the bottom of the central girder and prestressed CFRP laminates were attached to the bottom surface of one of the outer girders. Before and after strengthening the girders were loaded in order to investigate the bridge behaviour and the influence of strengthening. Thereafter a failure test of the strengthened girders was carried out, followed by a failure test of the bridge deck slab adjacent to the third girder still in function. The residual pre-stress forces were evaluated based on destructive and non-destructive methods, Bagge et al. (2014, 2017).

\subsection{Assessment Versus Test Results - Bridge Girders}

The bridge girders were loaded in middle of the second span. Based on linear elastic analysis and local resistance models according to the European standard (CEN 2005), the flexural capacity was reached adjacent to the mid-span at 9.1 MN. However, the flexural capacity at the supports was not fully utilized and, thus, redistribution of internal forces can be expected. According to the European standard up to $30 \%$ redistribution, in relation to the linear elastic distribution of internal forces, can be allowed for statically indeterminate structures without further verification of the deformation capacity of the plastic region. The approach taking redistribution into account resulted in the shear capacity reached at the support for a load of $10.4 \mathrm{MN}$. In-situ tested material parameters were used in the calculations, leading to a considerably improved load-carrying capacity compared to the values used at the design of the bridge.

In the test, the girders were first equally loaded up to total load of $12 \mathrm{MN}$, followed by increased load on the outer girder until failure at $13.4 \mathrm{MN}$. After a drop of the load, the inner girder was further loaded to failure at 12.8 MN. The same failure mechanism was observed for the two girders (see the failed girders in Fig. 6a). Extensive vertical and diagonal cracks were formed and both longitudinal non-prestressed reinforcement and vertical shear reinforcement yielded. In the final stage the stirrups crossing the critical diagonal ruptured and simultaneously the loading plate punched through the slab. In general, the structure behaved in a ductile manner and an appreciable residual load-carrying capacity remained after the test proving the bridge structure to be quite robust.

Comparison of the test results and the analytical calculations indicates difficulties to accurately predict the load-carrying capacity. Undoubtedly, redistribution of internal forces took place in the structure and should be taken into account in assessment. The shear model in the European standard (CEN 2005) in combination with linear elastic analysis with redistribution was not able to reflect the failure of the bridge. The load-carrying capacity was underestimated and the critical section was inaccurately located. 


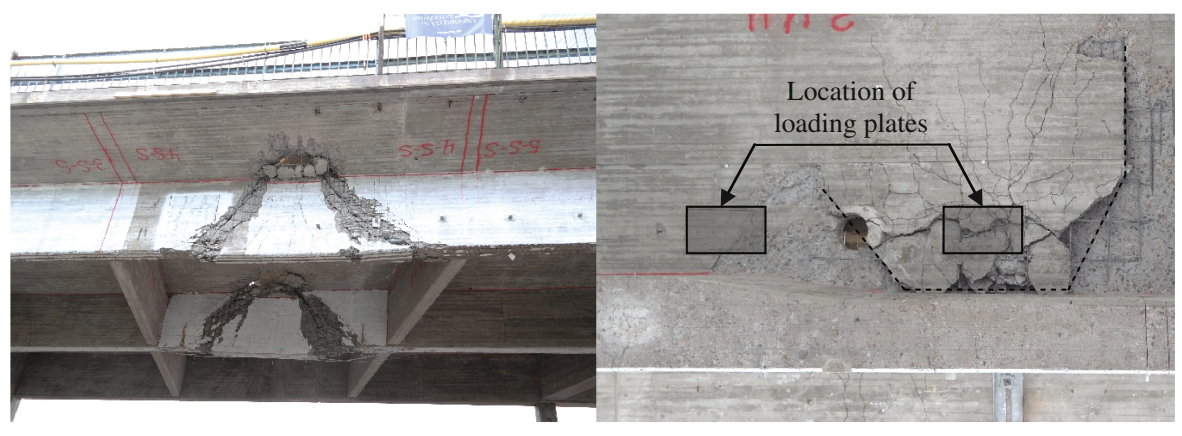

(a)

(b)

Fig. 6. Photograph of the Kiruna Bridge after test: (a) failure of the girders, view from south, and (b) failure of the slab, view from underneath.

\subsection{Assessment Versus Test Results - Bridge Deck Slab}

The bridge deck slab was loaded in the middle of the second span with two loading plates (2.0 m apart) adjacent to the girder not previously loaded to failure. Punching of the loading plate and shear at the girder, assuming $45^{\circ}$ shear distribution from the edge of the loading plate, was according to (CEN 2005) to determine the load-carrying capacity of the slab. Based on in-situ tested material parameters the one-way shear capacity was critical and the predicted load-carrying capacity was $1.48 \mathrm{MN}$. The test resulted in a sudden, brittle failure of the slab at a load of $3.32 \mathrm{MN}$. The failure was formed around one of the loading plates (see Fig. 6b) as a combination of shear and punching failure, initiated as a shear failure at the girder. Thus, the analytical models applied are too conservative and do not fully reflect the behaviour of the bridge deck slab under the current load situation. Refined analysis is needed and a procedure for an improved structural analysis has been suggested by Plos et al. (2017).

\section{Conclusions}

The three bridges had a considerable hidden capacity and the codes could not accurately predict the results. It is important to obtain experiences of the failure types and the real robustness/weakness of assessed bridges.

Acknowledgement. The authors acknowledge continuous support from funders and colleagues.

\section{References}

Bagge, N., Nilimaa, J., Blanksvärd, T., Elfgren, L.: Instrumentation and full-scale test of a post-tensioned concrete bridge. Nordic Concrete Res. 51, 63-83 (2014)

Bagge, N., Shu, J., Plos, M., Elfgren, L.: Punching Capacity of a Reinforced Concrete Bridge Deck Slab Loaded to Failure. Nordic Concrete Federation: Residual Capacity of Deteriorated Concrete Structure, Oslo, Norway (2015) 
Bagge, N., Nilimaa, J., Blanksvärd, T., Täljsten, B., Elfgren, L., Sundquist, H., Carolin, A.: Assessment and failure test of a prestressed concrete bridge. "Life-Cycle of Engineering Systems". Taylor \& Francis (2016). ISBN: 978-1-138-02847-0

Bagge, N., Nilimaa, J., Elfgren, L.: In situ methods to determine residual prestress forces in concrete bridges. Eng. Struct. 135, 41-52 (2017)

CEN: Eurocode 2: Design of concrete structures - Concrete bridges - Design and detailing rules SS-EN 1992-2:2005, Brussels, Belgium, p. 104 (2005)

Elfgren L, Enochsson O, Puurula A, Thun H.: Field Test of a Concrete Bridge in Örnsköldsvik. Report SB-7.3, 406 pp (2008) www.sustainablebridges.net

Elfgren, L.: Fatigue Capacity of Concrete Structures: Assessment of Railway Bridges. Research Report, Luleå University of Technology, 103 pp (2015)

Huang, Z., Grip, N., Sabourova, N., Bagge, N., Tu, Y., Elfgren, L.: Modelling of Damage and its use in Assessment of a Prestressed Bridge, p. 21. Luleå University of Technology, Luleå, Sweden (2016)

Nilimaa, J.: Concrete bridges: Improved load capacity. (Ph.D. Thesis), Luleå University of Technology, Luleå, Sweden, $176 \mathrm{pp}$ (2015)

Plos, M., Shu, J., Zandi, K.Z., Lundgren, K.: A multi-level structural assessment strategy for reinforced concrete bridge deck slabs. Struct. Infrastruct. Eng. 13(2), 223-241 (2017)

Paulsson, B., Töyrä, B., Elfgren, L., Ohlsson, U., Danielsson, G., Johansson, H, Åström, L.: 30 ton på Malmbanan. Rapport 3.3 Infrastruktur (Static tests on four trough bridges and a laboratory fatigue test on one bridge. In Swedish), Banverket (1996)

Paulsson, B., Bell, B., Schewe, B., Jensen, J. S., Carolin, A., Elfgren, L. Results and Experiences from European Research Projects on Railway Bridges. IABSE Congress Stockholm, Zürich, pp. 2570-2578 (2016). ISBN: 978-3-85748-144-4

Puurula, A.: Load-carrying Capacity of a Strengthened Reinforced Concrete Bridge: Non-linear Finite Element Modeling of a Test to Failure. Doctoral Thesis. Luleå University of Technology, Luleå, 332 p (2015)

Puurula, A., Enochsson, O., Sas, G., Blanksvärd, T., Ohlsson, U., Bernspång, L., Elfgren, L.: Loading to failure and 3D nonlinear FE modelling of a strengthened RC bridge. Struct. Infrastruct. Eng. 10(12), 1606-1619 (2014)

Puurula, A., Enochsson, O., Sas, G., Blanksvärd, T., Ohlsson, U., Bernspång, L., Täljsten, B., Carolin, A., Paulsson, B., Elfgren, L.: Assessment of the strengthening of an RC railway bridge with CFRP utilizing a full-scale failure test and finite-element analysis. J. Struct. Eng., ASCE 141, D4014008 (2012)

Puurula, A., Enochsson, O., Sas, G., Blanksvärd, T., Ohlsson, U., Bernspång, L., Täljsten, B., Elfgren, L.: 3D non-linear FE analysis of a full scale test to failure of a RC Railway Bridge strengthened with carbon fibre bars. In: IABSE Congress Stockholm 2016, Zürich, pp 25272535 (2016). ISBN 978-3-85748-144-4

Sustainable Bridges: Assessment for Future Traffic Demands and Longer Lives. A European FP 6 Integrated Research Project during 2003-2007 (2007). Four guidelines and 35 background documents www.sustainablebridges.net

Thun, H., Ohlsson, U., Elfgren, L.: Fatigue Capacity of Small Railway Concrete Bridges: Results of Swedish Full-scale Tests. Comparison and Analyses. Final Report ERRI D216, Structural Engineering, Luleå University of Technology, 99 pp (2000). http://ltu.diva-portal.org/smash/ get/diva2:998463/FULLTEXT01.pdf

Thun, H., Ohlsson, U., Elfgren, L.: A deformation criterion for fatigue of concrete in tension. Struct. Concr., J. fib 12(3), 187-197 (2011) 